\title{
Neoethilla, a new genus for the first record of the Ethillini from the New World (Diptera, Tachinidae, Exoristinae)
}

\author{
Pierfilippo Cerretti ${ }^{1,2, \dagger}$, D. Monty Wood ${ }^{3, \ddagger}$, James E. O’Hara ${ }^{3, \S}$ \\ I Dipartimento di Biologia e Biotecnologie "Charles Darwin", Università di Roma "La Sapienza", Piazzale A. \\ Moro 5, 00185, Rome, Italy 2 Centro Nazionale per lo Studio e la Conservazione della Biodiversità Forestale \\ - Corpo Forestale dello Stato, Via Carlo Ederle 16/A, 37100, Verona, Italy 3 Canadian National Collection of \\ Insects, Agriculture and Agri-Food Canada, 960 Carling Avenue, Ottawa, Ontario, Canada K1A 0C6 \\ † urn:lsid:zoobank.org:author:9F0694A5-5C84-4476-868A-16635A2DFAD2 \\ ¥ urn:lsid:zoobank.org:author:EF0E63AA-0B18-4B4E-885C-FF34980CDC27 \\ § urn:lsid:zoobank.org:author:C4301D99-72C0-45E1-ACDB-44D02A2E2FD4 \\ Corresponding author: Pierflippo Cerretti (pierfilippocerretti@yahoo.it)
}

Academic editor: M. Hauser | Received 10 September 2012 | Accepted7 November 2012 | Published 15 November 2012

urn:lsid:zoobank.org:pub:DE7F11FA-AD12-49D7-94E2-7E4FD82DB5F2

Citation: Cerretti P, Wood MD, O'Hara JE(2012) Neoethilla, a new genus for the first record of the Ethillini from the New World (Diptera, Tachinidae, Exoristinae). ZooKeys 242: 25-41. doi: 10.3897/zookeys.242.3974

\begin{abstract}
New genus Neoethilla gen. n., is described to include two New World nominal species formerly recognized as valid species in Winthemia Robineau-Desvoidy: Exorista ignobilis van der Wulp and Winthemia antennalis Coquillett. Winthemia antennalis is proposed as a junior synonym of Exorista ignobilis syn. $\mathbf{n}$. Neoethilla ignobilis comb. n. is removed from the Winthemiini and placed in the tribe Ethillini (Exoristinae) based on a study of the external features of adults, male terminalia, female reproductive system, and egg morphology. The small tribe Ethillini, not hitherto known from the New World, currently comprises fourteen genera worldwide. The phylogeny and systematics of the Ethillini and their relationships with related tribes are discussed and documented by descriptions and illustrations of relevant character states.
\end{abstract}

\section{Keywords}

Ethillini, Exorista ignobilis van der Wulp, Nearctic Region, Neotropical Region, Winthemia antennalis Coquillett, new genus, new synonymy, phylogeny, systematics, Winthemiini

Copyright Pierfilippo Cerretti et al. This is an open access article distributed under the terms of the Creative Commons Attribution License 3.0 (CC-BY), which permits unrestricted use, distribution, and reproduction in any medium, provided the original author and source are credited. 


\section{Introduction}

Van der Wulp (1890) described Exorista ignobilis from Guerrero, Mexico, based on a single male. The species was subsequently moved to Winthemia Robineau-Desvoidy, 1830, by Reinhard (1931) and has continued to be treated as a valid species of Winthemia to the present day (Guimarães 1972). However, Reinhard (1931) misidentified the species; he did not examine the holotype of E. ignobilis but instead relied on notes taken of it by J.M. Aldrich in 1929. Based on these notes, Reinhard (1931) misidentified three specimens from Chile and Argentina as Winthemia ignobilis and redescribed the species from this material. Aldrich (1934) himself accepted the identifications of Reinhard (1931) and included the species under the same combination in his faunal treatment of the Tachinidae of Patagonia and South Chile. Cortés and Hichins (1969) also recognized a Chilean species of Winthemia as W. ignobilis. Although the identities of these specimens from Chile and Argentina have yet to be clarified, we suspect that everything once called W. ignobilis from these countries is W. reliqua Cortés \& Campos, 1971.

A second nominal species, Winthemia antennalis, was later described by Coquillett (1902) based on a single female from Los Angeles County, California, United States. Coquillett (1897) had earlier misidentified this single specimen as Winthemia nigrifacies (Bigot, 1889) in his key to the species of Winthemia of America north of Mexico. Tothill (1912) continued the placement of this species in Winthemia in his key to the North American species of the genus, as did Reinhard (1931) in his revision of the "American" species of Winthemia. This classification was also followed by Sabrosky and Arnaud (1965) in the Catalog of the Diptera of America north of Mexico. Guimarães (1972), however, removed W. antennalis from Winthemia in his revision of the Winthemia of America north of Mexico. Without further explanation, he wrote in his abstract: "Winthemia antennalis Coquillett does not belong in this genus and its correct placement has not been determined" (Guimarães 1972: 27). Sabrosky (1973) apparently agreed, as he did not include $W$. antennalis in his paper on the identification of Winthemia species of America north of Mexico.

Winthemia antennalis was again treated as a Winthemia species, albeit provisionally, by Wood (1987). Wood (1987: 1210) explained this placement in a footnote: "Although arrangement of postpronotal bristles is different from other species of Winthemia, the male terminalia and unembryonated planoconvex egg suggest a relationship, which may ultimately be resolved by additional study of the tribe Winthemiini”. Recently, O'Hara and Wood (2004) maintained this classification and listed W. antennalis under Winthemia in their catalogue of the Tachinidae of America north of Mexico.

The enigmatic placement and identity of E. ignobilis and W. antennalis became a topic of discussion among us when several specimens provisionally identified as $W$. antennalis were collected in the Gila National Forest of New Mexico, United States, during the field meeting of the North American Dipterists Society in 2007. Upon 
further study we have determined that $W$. antennalis Coquillett is a junior synonym of E. ignobilis van der Wulp and that this taxon belongs not to the Winthemiini but to the Ethillini, a tribe hitherto unknown from the New World. We discuss below the characteristics of the Ethillini and propose a new genus for the single known New World species of this tribe.

\section{Materials and methods}

\section{Specimens}

Male terminalia of Neoethilla ignobilis were dissected following the method described in detail by O'Hara (2002), then dehydrated with ethanol and critical point dried. After examination, the terminalia were rehydrated and preserved in glycerine in a plastic microvial pinned below the specimen (cf. Cerretti and Shima 2011). One egg, almost entirely exposed but still attached to the ovipositor of a dried female of $N$. ignobilis from Plymouth, Massachusetts (CNC), was removed by tilting it carefully with a pin and then mounted on a micropin. After ESEM examination the egg was glued on a tag and pinned below the source specimen. Male terminalia, pinned specimens and egg were examined, uncoated, with a Hitachi TM1000 environmental scanning electron microscope (ESEM); male terminalia were also slide mounted and examined with a Leica DMLS. Figures 1a-e were prepared from composites of images captured using a Canon EOS 40D Digital SLR camera body, with a Canon MP-E 65mm 1-5X macro lens, mounted on a Kaiser RS1 copy stand (for further details see O'Hara 2012); figures $5 \mathrm{a}-\mathrm{c}$ were prepared from composites of images captured with a Nikon Digital Sight DS-L1, DS-5M mounted on a Leica DMLS. Specimens examined are preserved in the following collections (acronyms used in the text):

BMHN Natural History Museum [formerly British Museum (Natural History)], London, United Kingdom (N. Wyatt).

CNC Canadian National Collection of Insects, Agriculture and Agri-Food Canada, Ottawa, Canada.

MZUR Museum of Zoology, Università degli Studi di Roma "La Sapienza”, Rome, Italy (A. Vigna Taglianti).

USNM National Museum of Natural History [formerly United States National Museum], Smithsonian Institution, Washington, United States (N.E. Woodley).

Label data of the holotypes of E. ignobilis and $W$. antennalis are cited verbatim with the end of lines and labels indicated by the following symbols: /, end of a line and beginning of the next; //, end of a label and beginning of the next (from top to bottom on the same pin). 


\section{Terminology}

Morphological terminology generally follows McAlpine (1981), except for the antenna and a few details of thoracic chaetotaxy for which we are following Stuckenberg (1999) and Tschorsnig and Richter (1998), respectively. Measurements and ratios of the head follow Cerretti (2010).

\section{Systematics}

Neoethilla gen. n.

urn:lsid:zoobank.org:act:2863EDC7-20B9-4102-AD19-4EF4CFFA6120

http://species-id.net/wiki/Neoethilla

Figs 1a-f, 2a-b, 4a-d, 5a-e

Type species: Exorista ignobilis van der Wulp, 1890, by present designation.

Etymology. The compound name Neoethilla refers to the New (Latin, neo) World distribution and to the suspected close relationship of this genus with the Old World genus Ethilla Robineau-Desvoidy, 1863.

Description. This generic description is based on a redescription of the single included species, $N$. ignobilis.

Length: $5.5-7.5 \mathrm{~mm}$.

Colour: Head mainly black, covered with grey microtomentum. Palpus black to brown (usually paler in female). Thorax and legs entirely black. Abdomen mainly black but reddish yellow laterally (Fig. 1a-b). Tegula and basicosta black.

Head (Figs 1a-e, 2a): Large in dorsal view, about as wide as thorax; higher than long in lateral view. Compound eye densely covered with long ommatrichia (Fig. $1 \mathrm{c}-\mathrm{f})$. Frons at its narrowest point 2/3-6/7 ( $\hat{0}$ \%) as wide as eye in dorsal view (no significant sexual dimorphism in examined specimens). Frontal vitta (= interfrontal area) clearly widening anteriorly. Outer (= lateral) vertical seta not differentiated from postocular setae in male, well developed in female. Ocellar seta absent (Figs 1c-d, 2a) or very small; ocellar triangle with several short, proclinate setulae (Fig. 2a). Frontoorbital plate of male with about three irregular rows of fine, medioclinate setae lateral to frontal setae. Seven to 10 frontal setae. Two or 3 upper (= dorsal) reclinate orbital setae, often not clearly differentiated from frontal setae. Proclinate orbital setae absent in male, 2 in female (Fig. 1a-b). Parafacial covered with proclinate, short, fine setae (Fig. 1a-b, 1e-f). Facial ridge straight in profile, with only a few setae above vibrissa on about $1 / 5-1 / 4$ of its length. Vibrissa arising at about level of lower facial margin. Face concave; lower facial margin not visible in profile. Antenna slightly shorter than facial ridge. Postpedicel 3.0-3.5 times as long as pedicel. Arista bare, thickened on basal $2 / 5-1 / 2$. First aristomere not longer than wide (usually shorter); second aristomere 1-2 times as long as wide. Genal dilation well developed. Gena in profile very narrow, about $0.10-0.15$ times as high as compound eye (height measured in the same vertical 

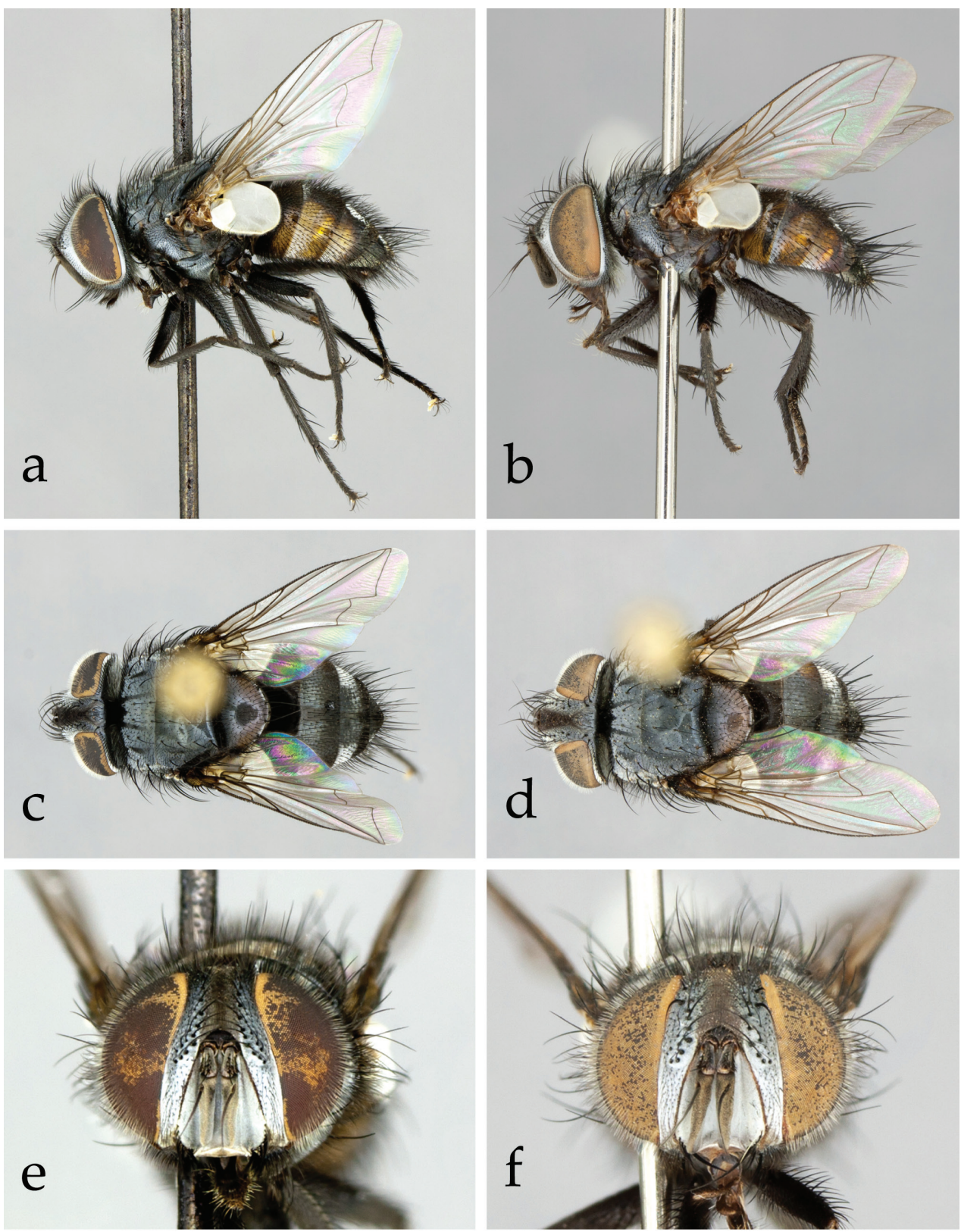

Figure I. Neoethilla gen. n. ignobilis (New Mexico) a-d habitus a male in lateral view $\mathbf{b}$ female in lateral view $\mathbf{c}$ male in dorsal view $\mathbf{d}$ female in dorsal view $\mathbf{d}$-e head in frontal view $\mathbf{d}$ male $\mathbf{e}$ female.

plane as height of head). Postocular setae fine, relatively long and slightly bent anteriorly. Occiput flat, with 1-2 rows of black setulae behind postocular row. Prementum not more than 2 times as long as wide; palpus well developed, apically covered with setulae, often strongly clavate in female. 

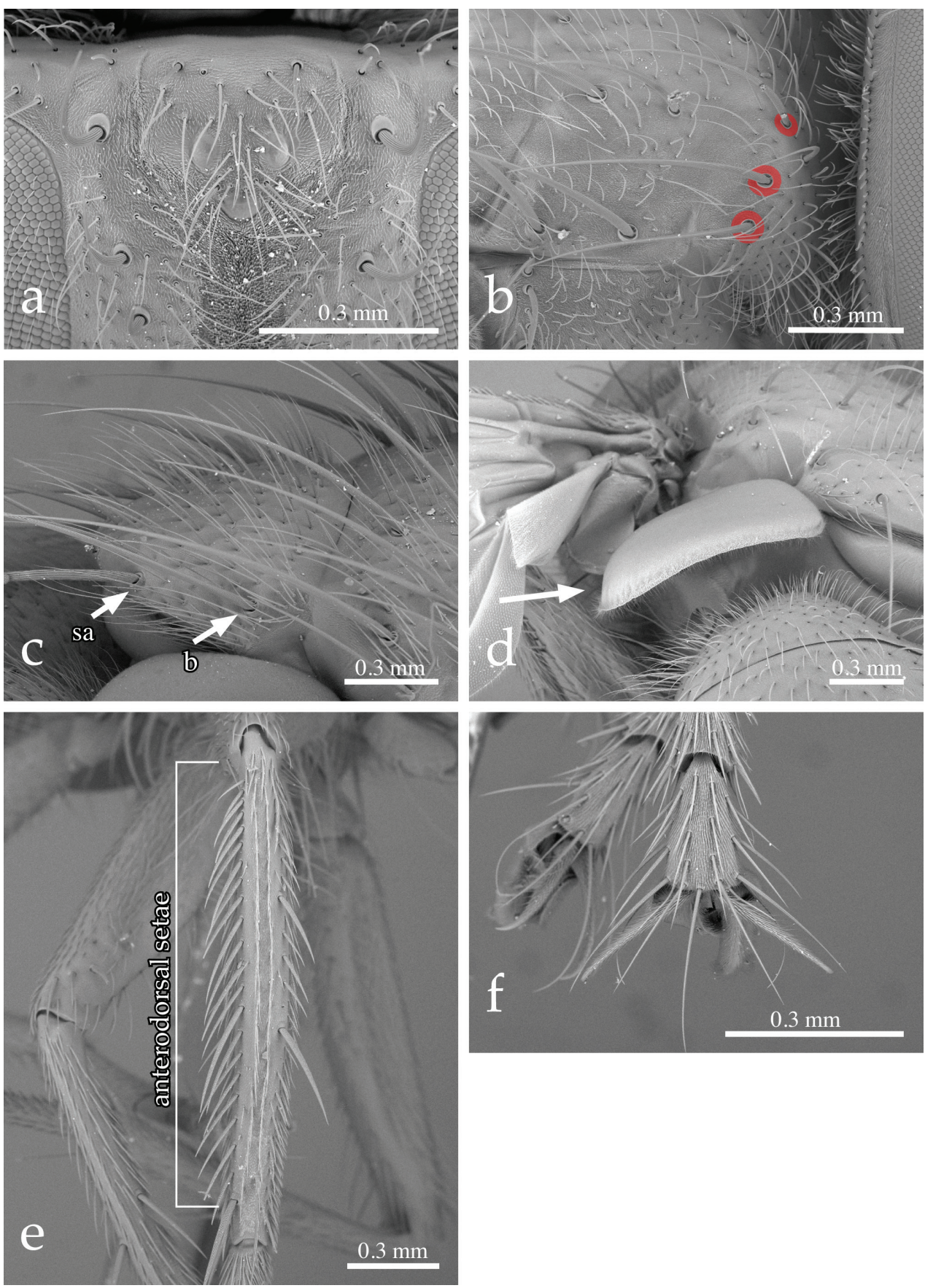

Figure 2. Neoethilla gen. n. ignobilis (male, New Mexico) a vertex in anterodorsal view b right postpronotum and part of presutural portion of scutum in laterodorsal view [circles indicate basal postpronotal saetae] c scutellum in laterodorsal view [b = basal scutellar seta; $\mathrm{sa}=$ subapical scutellar seta] d lower calypter in posterior view $\mathbf{e}$ left hind tibia in dorsal view $\mathbf{f}$ fore claws. 


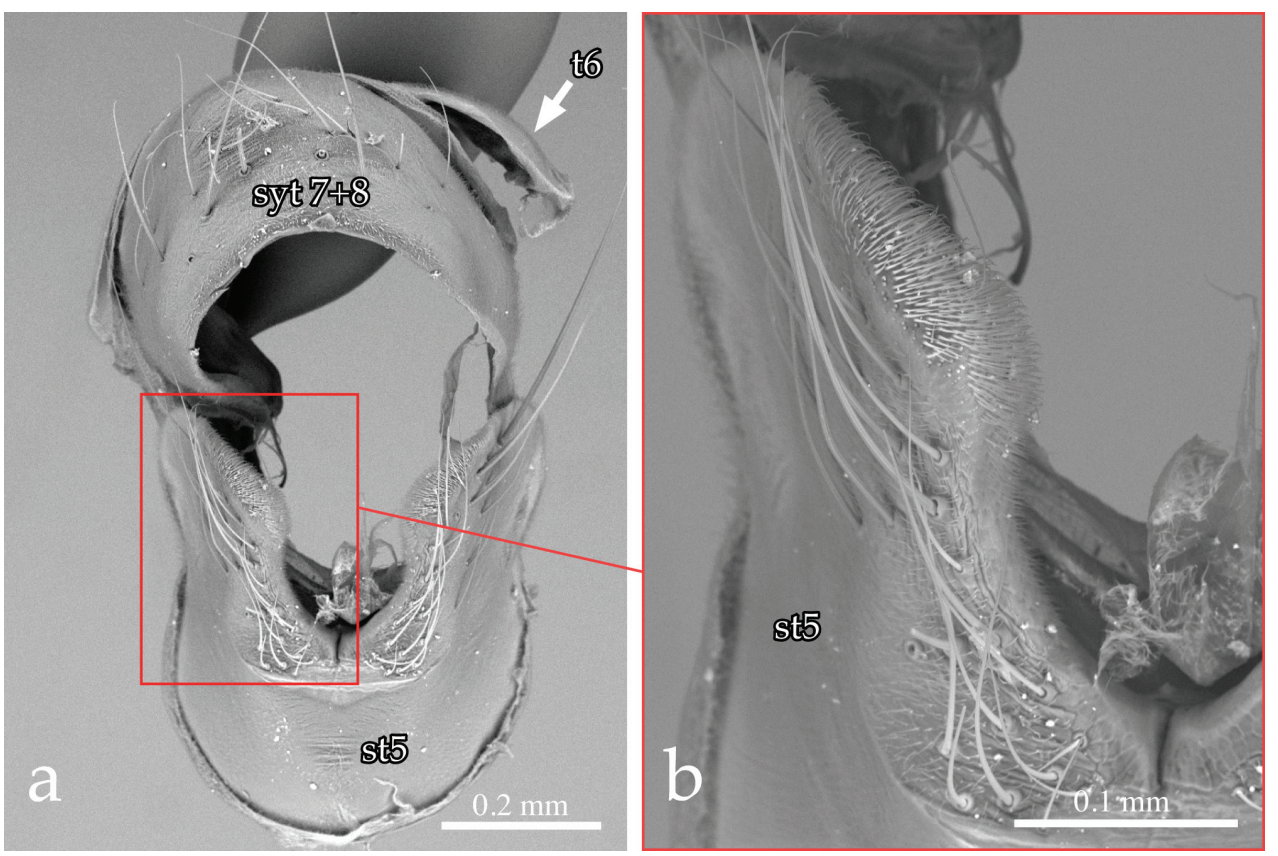

Figure 3. Neoethilla gen. n. ignobilis (male, New Mexico) [st5 = sternite $5 ; \mathbf{s y t} 7+\mathbf{8}=$ syntergite $7+8 ; \mathbf{t} \mathbf{6}=$ tergite 6] a sternite 5 and syntergite $7+8 \mathbf{b}$ detail of left lobe of sternite 5 .

Thorax (Figs 1a-d, 2b-d): Postpronotum with 4 setae; 3 strongest, basal, arranged in a line (Fig. $2 b$ ). Scutum with $2-3$ posthumeral setae, $1+3$ supra-alar (first postsutural supra-alar seta at most as long as a notopleural seta), $0-1+3$ intra-alar, $3+$ 4 dorsocentral, $3+3$ acrostichal setae. General hair-like setulae of scutum fine, relatively long and erect. Prosternum laterally setose. Proepisternal depression bare. Two katepisternal setae (the posterior one larger). Katepimeron setulose along its length. Anepimeral seta at most half as long as posterior katepisternal seta. Scutellum wider than long, covered with long, fine, erect setulae. Three pairs of marginal scutellar setae (basal, subapical, apical) (Figs 1c-d, 2c); basal and subapical setae about equal in size; apical pair shorter, crossed and sub-horizontal. Scutellum without discal setae. Anterior and posterior lappets of metathoracic spiracle unequal in size.

Legs: Preapical anterodorsal seta of fore tibia about as long and stout as preapical dorsal seta. Mid tibia with 1 anterodorsal seta. Hind tibia with a row of moderately spaced, comb-like anterodorsal setae (Fig. 2e); 2 dorsal preapical setae. Preapical posteroventral seta of hind tibia not differentiated. Claws about as long as fifth tarsal segment in male (Fig. 2f), considerably shorter in female.

Wing (Figs 1a-d, 2d): Bend of vein M usually obtuse. Cell $\mathrm{r}_{4+5}$ open. Section of $\mathrm{M}$ between crossveins $\mathrm{r}-\mathrm{m}$ and $\mathrm{dm}-\mathrm{cu}$ longer than section between $\mathrm{dm}-\mathrm{cu}$ and bend of M. Section of M between $\mathrm{dm}-\mathrm{cu}$ and bend of $\mathrm{M}$ shorter than post-angular section of $\mathrm{M}$. Vein $\mathrm{R}_{4+5}$ with a single setula at base dorsally and $0-1$ ventrally. 

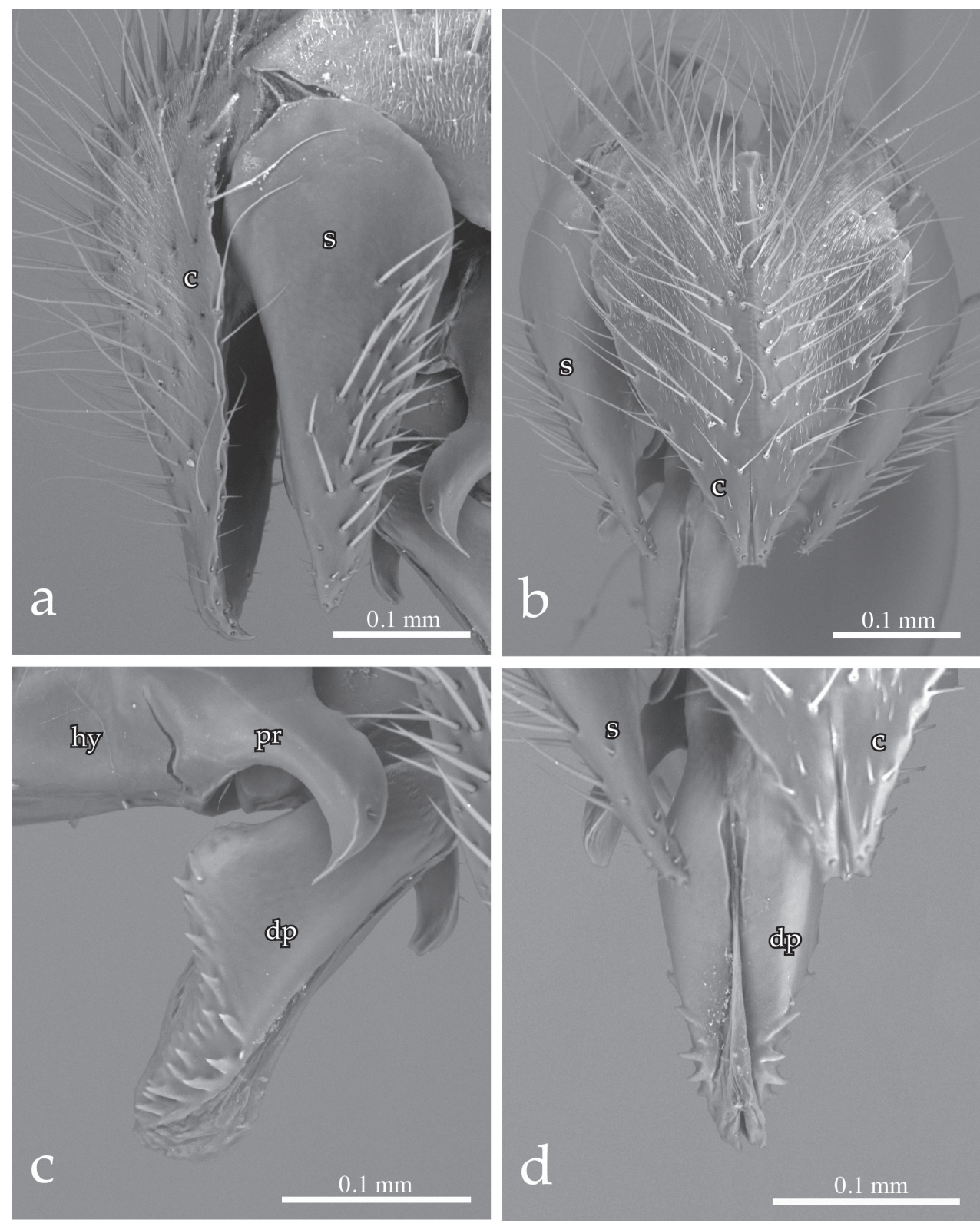

Figure 4. Neoethilla gen. n. ignobilis (male, New Mexico) [c = cerci; hy = hypandrium; dp = distiphallus; $\mathbf{p r}=$ pregonite; $\boldsymbol{s}=$ surstylus] $\mathbf{a}$ cerci and right surstylus in lateral view $\mathbf{b}$ epandrial complex in posterior view $\mathbf{c}$ distiphallus and pregonite in left lateral view $\mathbf{d}$ distiphallus in dorsal view.

Lower calypter large and strongly convex, especially along its lateral and posterior margins (Fig. 2d).

Abdomen (Fig. 1a-d): Syntergite 1+2 with mid-dorsal depression extending to hind margin. Tergites $1+2$ and 3 with a pair of fine median marginal setae, sometimes 


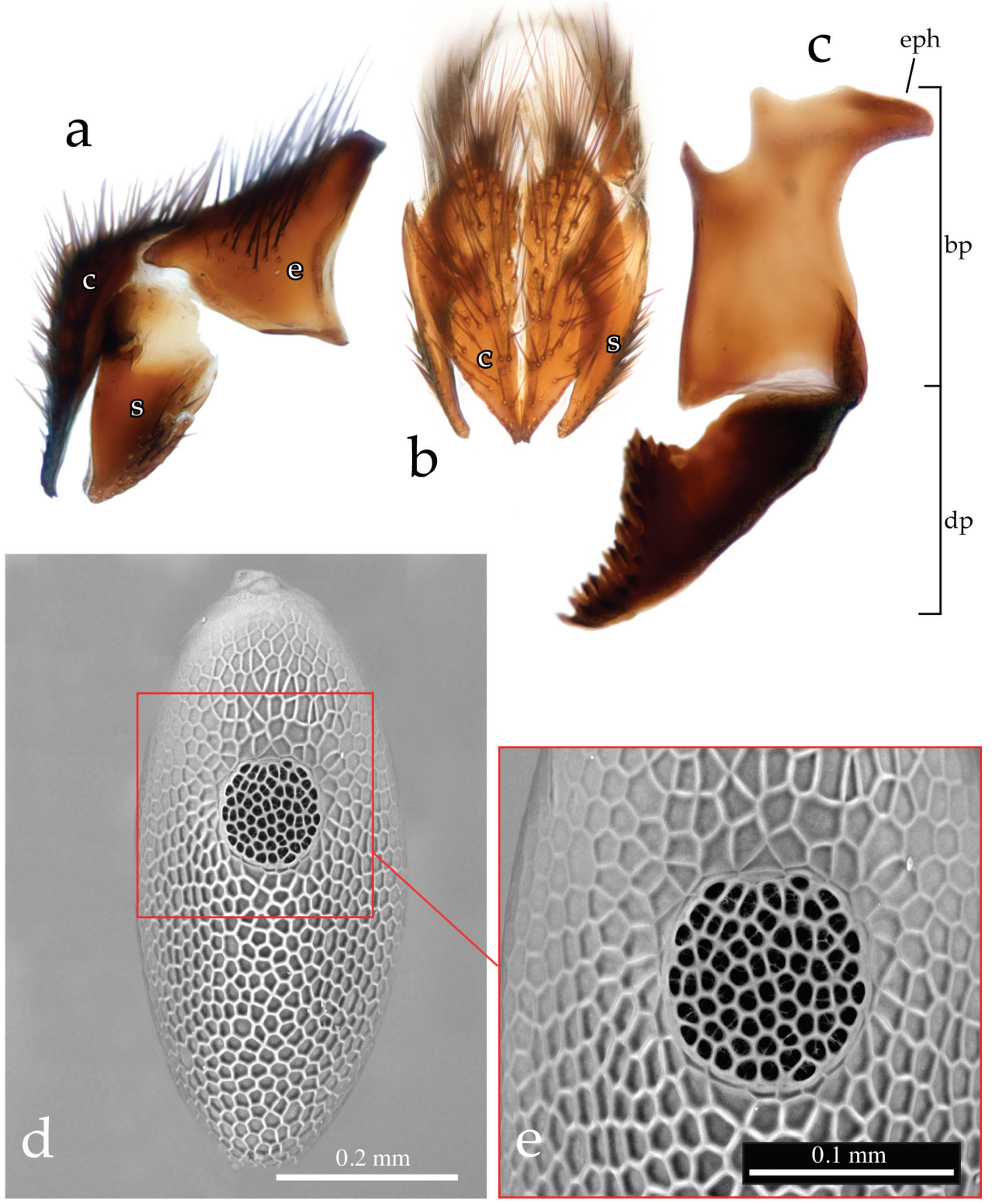

Figure 5. Neoethilla gen. n. ignobilis $\mathbf{a}-\mathbf{c}$ terminalia (male, Idaho) $[\mathbf{c}=$ cerci; $\mathbf{b p}=$ basiphallus; $\mathbf{d p}=$ distiphallus; $\mathbf{e}=$ epnadrium; $\mathbf{e p h}$ = epiphallus] $\mathbf{a}$ epandrial complex in lateral view $\mathbf{b}$ epandrial complex in posterior view $\mathbf{c}$ phallus in lateral view $\mathbf{d}$-e egg in dorsal view (Massachusetts) $\mathbf{d}$ habitus $\mathbf{e}$ detail of operculum.

not differentiated from the general abdominal setae, and a pair of lateral setae; tergite 4 with a row of marginal setae; tergite 5 with scattered weak setae. Tergites 3 and 4 without median or lateral discal setae.

Male terminalia (Figs 3a-b, 4a-d, 5a-c): Sternite 5 with deep median cleft, outer lobe almost truncate along posterior margin (Fig. 3a-b). Tergite 6 large, plate-like 
(not divided into two sclerites nor indentate on posterior edge), bare; tergite 6 separated from tergite 5 and segment $7+8$ by membrane. Cerci (Figs. 4a-b, 5a-b) almost flat, wide in posterior view (sub-ovoid), not fused medially (i.e., longitudinal medial suture complete), distally very slightly divided (Figs 4b, 4d, 5b). Surstylus long, wide and sub-triangular in lateral view, distal tip sometimes slightly bent posteriorly (Figs $4 c, 5 a)$. Posterior half of lateral surface of surstylus with several stout setae. Pregonite and postgonite not fused. Pregonite strongly recurved and pointed. Processi longi long, slender and well separated from each other. Epiphallus stout, well sclerotized, attached to basal portion of basiphallus (Fig. 5c). Connection between basiphallus and distiphallus strongly sclerotized (Fig. 5c). Lateroventral sclerites of distiphallus well developed, strongly sclerotized with robust spines lateroventrally (Figs 4a-b, 5c).

Female terminalia. Ovipositor short, not telescopic as in Winthemiini.

Egg. Plano-convex macrotype unembryonated; long-oval in dorsal view; anterodorsally operculate (Fig. 5d-e). Dorsal, convex surface of egg characterized by a strong polygonal micro-sculpturing.

Remarks. Neoethilla is superficially similar to Winthemia because it has an enlarged compound eye covered with thick and long ommatrichia and parafacial covered with fine setulae. Moreover, Neoethilla and Winthemia both have a short first postsutural supra-alar seta, a comb-like row of anterodorsal setae on hind tibia and a fully setulose katepimeron. Neoethilla is distinguishable from Winthemia (i) in having the three strongest basal setae of postpronotum arranged in a line, (ii) in lacking the lateral scutellar setae and (iii) in having processi longi of male terminalia long, slender and well separated from each other. Females of Neoethilla have a short ovipositor and a dorsally operculate plano-convex egg. These characters, together with the strongly convex lower calypter, suggest that Neoethilla has an ethilline affiliation. Within this tribe the new genus is characterized by the following combination of character states: (i) parafacial fully setulose, (ii) gena very narrow $(0.10-0.15$ times as high as compound eye), (iii) ocellar setae absent or very reduced, (iv) three strongest basal postpronotal setae arranged in a line, and (v) lateral scutellar setae missing.

\section{Included species and examined specimens}

Neoethilla ignobilis (van der Wulp, 1890), comb. n.

http://species-id.net/wiki/Neoethilla_ignobilis

Exorista ignobilis van der Wulp, 1890: 71. Type material examined: holotype $\widehat{\partial}$ (BMNH): HOLO- / TYPE [disc with red border] // $\delta / /$ Amula, / Guerrero, / 6000 ft. / Aug. H.H.Smith. // B.C.A. Dipt.II. / Exorista / ignobilis, / v.d.W. // Central America. / Pres. by / F.D.Godman. / O.Salvin. / 1903-172. // HOLOTYPE / of Exorista / ignobilis Wulp / designated 1998 / D.M. Wood.

Winthemia antennalis Coquillett, 1902: 115, syn. n. Type material examined: holotype + (USNM): Los Angeles / Co., CAL. // JULY // Collection / Coquillett // Type / No 6222 / U.S.N.M. [red label] // Winthemia / antennalis / Coq. 
Other material examined. UNITED STATES. Arizona: 1 त, Cochise County, Chiricahua Mountains, $1760 \mathrm{~m}, 31^{\circ} 52^{\prime} 26.1^{\prime \prime N}, 109^{\circ} 13^{\prime} 55.8^{\prime \prime W}, 18 . V I I I .2007$, P. Cerretti leg.

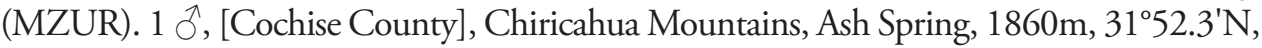
109¹4.7'W, 20-21.IX.2004, J.E. O'Hara leg. (CNC). 3 우, [Cochise County], Huachuca Mountains, Ramsey Canyon, 1680 m, 2.V.1967, D.M. Wood leg. (CNC). 1 , Cochise County, [Huachuca Mountains], Ida Canyon, $1800 \mathrm{~m}, 31^{\circ} 23.5^{\prime} \mathrm{N} 110^{\circ} 19^{\prime} \mathrm{W}$, 22-24.X.2001, G. \& M. Wood leg. (CNC). 1 đે, Coconino County, 2 km w. Sunset Crater National Monument, 2100 m, 23-24.VII.1982, J.E. O'Hara leg. (CNC). California: 2

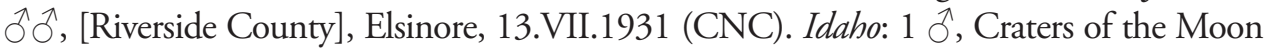
National Monument, 8.VII.1965, D.S. Horning Jr. leg. (CNC). Maryland: 1 ô, Calvert County, Port Republic, 21.VIII.2001, D.M. Wood leg. (CNC). Massachusetts: 1 q (with egg), Plymouth County, Onset, 29.VI-6.VII.1983, W.J. Morse leg. (CNC). New Mexico: 1 J , Grant County, 21 km n. Silver City, Cherry Creek Campground, 2100 m [not 2250 $\mathrm{m}$ or $7400^{\prime}$ as printed on some labels from this locality], $32^{\circ} 54.8^{\prime} \mathrm{N} 108^{\circ} 13.6^{\prime} \mathrm{W}, 16-19$. VIII.1982, J.E. \& W.M. O'Hara leg. (CNC). 1 O’, same data except 14-16.VIII.1983,

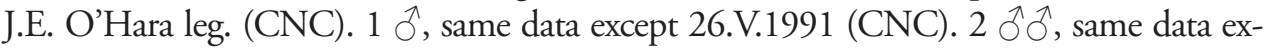

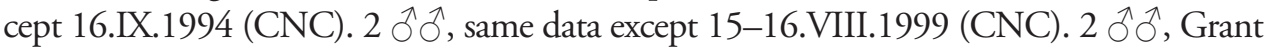
County, n. Silver City, Gomez Peak (hilltop), 2200 m, 3250'N 108¹7'W, 23.IX.2004,

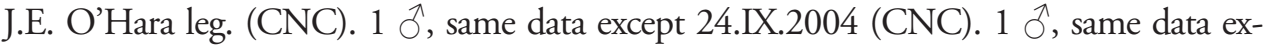
cept 27.VIII.2006 (CNC). 1 ô, same data except 9.VIII.2007 (CNC). 1 ô, same data

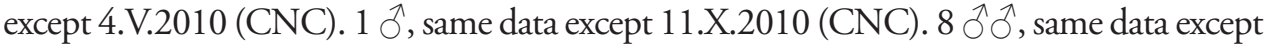

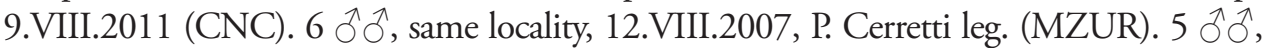
Grant County, n. Silver City, Eighty Mountain (hilltop), 2275 m, 3250.9'N 108 $18.0^{\prime} \mathrm{W}$,

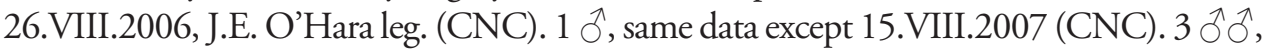
same locality, 15.VIII.2007, D.M. Wood leg. (CNC). 1 \%, Grant/Sierra County, 63 km e. Silver City, Emory Pass, 2500 m, 3254'N 10745'W, 12.VIII.2007, G.\& M. Wood leg. (CNC). $3{ }^{\AA}{ }^{\AA}$, Torrance Co., $14 \mathrm{~km}$ s. Cedarvale, North Peak (hilltop), $2250 \mathrm{~m}, 34^{\circ} 16.4^{\prime} \mathrm{N}$ 10543.5'W, 7.VIII.2007, J.E. O'Hara leg. (CNC). South Carolina: 1 Ô, Oconee Co., Sumter [as "Sumpter"] National Forest, Hunt Camp, 1.V.1997, M. Wood leg. (CNC).

Distribution. Neotropical: Mexico (Guerrero); Nearctic: widespread in continental United States (O’Hara and Wood 2004).

\section{Discussion}

The Ethillini are a small tribe of Exoristinae formerly thought to be exclusively Old World in distribution. Most Ethillini share a number of character states with several members of Winthemiini but the relationships between these tribes remain unclear as they have not been investigated with a rigorous cladistic approach. The tribe can be defined by the following character states:

(1) Lower calypter strongly convex (Fig. 2d) - this is a very rare condition in the Tachinidae (as well as in other Calyptratae) and could arguably be considered apomor- 
phic. Excluding Mycteromyiella Mesnil, 1966 and Calliethilla Shima, 1979, whose systematic placements in Ethillini are questionable (see also Crosskey 1984; Shima 1979; Cerretti 2012), all the other ethilline taxa share this character state. Interestingly, a very convex lower calypter is also present in a few species of Winthemia. This could easily be interpreted as convergence if not for the fact that Winthemiini also share other character states with Ethillini (see below),

(2) katepimeron usually entirely covered with fine setulae - within the subfamily Exoristinae this character state is shared with practically all known Winthemiini, a few Exorista and the exoristine genus Crassicornia Kugler, 1980 (cf. Cerretti et al. 2012; Cerretti 2012). Important exceptions exist for Atylomyia Brauer, 1898 and a few Amnonia Kugler, 1971 where the katepimeron is often entirely bare, and

(3) female ovipositor short (i.e., non-telescopic) - this could be a plesiomorphic condition compared to the long and telescopic one present in all Winthemiini.

In addition to the above states, all examined female ethillines have a macrotype plano-convex egg of white color. All the Exoristinae, most Phasiinae and the Eutheriini also have a plano-convex egg, or at least traces of a primitive planoconvex shape. This type of egg thus represents a plesiomorphic condition for Ethillini. It is worth noting that Ethillini show two reproductive strategies (Tschorsnig 1988): females with a short ovisac that lay unincubated eggs and females with a long ovisac in which eggs are stored until embryogenesis is complete (Paratryphera-group, see below).

Worldwide the following genera fall well within the above limits: Amnonia, Atylomyia, Ethilla, Ethylloides Verbeke, 1970, Gynandromyia Bezzi, 1923, Nemorilloides Brauer \& Bergenstamm, 1891, Neoethilla gen. n., Paratryphera Brauer \& Bergenstamm, 1891, Phorocerosoma Townsend, 1927, Prosethilla Herting, 1984, and Zelindopsis Villeneuve, 1943. As mentioned above, Calliethilla and Mycteromyiella have a questionable ethilline affiliation because of the lack of the distinctive convex lower calypter.

The grasshopper parasitoids Gynandromyia and Phorocerosoma and the genus Zelindopsis (Phorocerosoma-group) share the following: postpronotum with five setae, with the three basal strongest arranged in a triangle; female sternites 4-6 very large and exposed from the ventrolateral margins of the corresponding tergites; and egg surface dorsally smooth with two aeropilar areas, irregular in shape. The number and disposition of postpronotal setae are exactly the same as in nearly all the Winthemiini, and the egg characteristics are shared with several other Exoristinae. However, the features of the female abdominal sternites appear to be unique within the Exoristinae and may represent a strong apomorphy in support of the monophyly of this group of ethilline genera. Interestingly, males of Mycteromyiella share with males of several species of the Phoroserosoma-group the presence of distinctive spots of setulae and microtrichia on the ventral side of abdominal tergites 4 and 5, and also its members are parasitoids of Phasmatodea (Shima 1976), which are currently considered the living sister-group of the Orthoptera (cf. Grimaldi and Engel 2005).

All the remaining ethilline genera (Ethillini s. str.) share the following, probably derived, character states: 
(1) postpronotum with the three strongest, basal, setae arranged in a line (Fig. 2b),

(2) male tergite 6 bare, wide and not indented antero-medially,

(3) male segment 7+8 very wide and platiform (cf. Tschorsnig 1985), and

(4) egg distinctly operculate (Tschorsnig 1988) (Fig. 5d-e).

The presence of operculate eggs is a very rare condition in tachinids. In most Exoristini an operculum is delineated by a line at the anterior end of the egg (cf. Wood 1972; Cerretti 2010), in Eutherini an oval "window" is situated on the dorsal surface of the egg immediately in front of its posterior end (Herting 1966), while in Ethillini s. str. an operculum is situated on the dorsal surface of the egg in its anterior half or in the middle (cf. Tschorsnig 1988; Tschorsnig and Richter 1998). Such substantial differences in the shape and position of the operculum in these groups suggest that the three types may have evolved independently and thus be non-homologous. Based on the four states listed here we consider the Ethillini s. str. to be a monophyletic lineage.

Finally, two probably monophyletic groups may be identified within Ethillini s. str. (cf. Tschorsnig 1985; Cerretti 2010). The first is the Paratryphera-group, composed of Amnonia, Atylomyia and Paratryphera. These taxa share the following character states:

(1) long ovisac for storing fully embryonated eggs,

(2) pregonite and postgonite at least partly fused basally,

(3) connection between male sternite 6 and segment $7+8$ on right side very narrow,

(4) intermedium (cf. Tschorsnig 1985) not differentiated,

(5) epiphallus light-colored and attached to apical portion of basiphallus,

(6) ventrolateral sclerites of distiphallus greatly reduced, and

(7) dorsal connection between basiphallus and distiphallus almost membranous.

The second probably monophyletic group within Ethillini is the Ethilla-group, composed of Ethilla, Nemorilloides, Prosethilla and Neoethilla gen. n. These taxa share the following character states:

(1) short ovisac, females lay unembryonated eggs,

(2) pregonite and postgonite not fused,

(3) connection between male sternite 6 and segment $7+8$ on right side very wide,

(4) intermedium very large,

(5) epiphallus massive and attached to basal portion of basiphallus (Fig. 5c),

(6) ventrolateral sclerites of distiphallus heavily sclerotized and covered with spinulae (Figs 4c-d, 5c), and

(7) dorsal connection between basiphallus and distiphallus heavily sclerotized (Fig. 5c).

We transfer the New World species Exorista ignobilis van der Wulp to the Ethillini and assign it to the new genus Neoethilla based on its distinctive characteristics. Neoethilla may share a sister-group relationship with Prosethilla, as evidenced by its 
lack of lateral marginal setae on the scutellum and similar egg morphology (operculum, microsculpture and shape very similar in these genera, judging from figures of Prosethilla by Tschorsnig (1988)). Neoethilla is clearly distinguishable from Prosethilla by its very large compound eye that occupies most of the head in lateral view (gena very narrow, compared to $1 / 3$ or more of vertical eye height in Prosethilla), parafacial entirely covered with fine setulae (as in Winthemia), and ocellar setae not (or just slightly) differentiated from other setulae on the ocellar triangle.

\section{Acknowledgements}

We thank Norman Woodley (USNM) and Nigel Wyatt (BMNH) for assistance during examination of type material under their care; NW also kindly provided us with detailed images of the type specimen and labels of Exorista ignobilis. We are most grateful to Shannon Henderson and Alan Fleming (both at CNC) for the montaged images in figures 1a-f, to Massimo Lopresti and Giuseppe Lo Giudice (both at Centro Nazionale per lo Studio e la Conservazione della Biodiversità Forestale, Verona, Italy) for helping to compose figures 2-5, and to Hans-Peter Tschorsnig (Staatliches Museum für Naturkunde, Stuttgart, Germany) and an anonymous reviewer for their constructive comments on an earlier draft of this manuscript. This work was partially supported by U.S. NSF DEB-1146269.

\section{References}

Aldrich JM (1934) Tachinidae. In: Diptera of Patagonia and South Chile based mainly on material in the British Museum (Natural History). Part VII. Fascicle 1. London, 1-170.

Bezzi M (1923) Diptera, Bombyliidae and Myiodaria (Coenosiinae, Muscinae, Calliphorinae, Sacrophaginae, Dexiinae, Tachininae), from the Seychelles and neighbouring islands. Parasitology 15: 75-102. doi: 10.1017/S0031182000014542

Bigot JMF (1889) Diptères nouveaux ou peu connus. 34e partie. XLII. Diagnoses de nouvelles espèces. Annales de la Société Entomologique de France, Ser. 6, 8: 253-270.

Brauer F (1898) Beiträge zur Kenntniss der Muscaria schizometopa. I. Bemerkungen zu den Originalexemplaren der von Bigot, Macquart und Robineau-Desvoidy beschriebenen Muscaria schizometopa aus Sammlung des Herrn G.H. Verrall. Zweite Folge. Sitzungsberichte der Mathematisch-Naturwissenschaftliche Classe der Kaiserlichen Akademie der Wissenschaften in Wien. Abteilung I 107: 493-546.

Brauer F, Bergenstamm JE (von) (1891) Die Zweiflügler des Kaiserlichen Museums zu Wien. V. Vorarbeiten zu einer Monographie der Muscaria schizometopa (exclusive Anthomyidae). Pars II. Wien, 142 pp.

Cerretti P (2010) I tachinidi della fauna italiana (Diptera Tachinidae), con chiave interattiva dei generi ovest-paleartici. Cierre Edizioni, Verona. Volume I, 573 pp. Volume II (atlante iconografico), 339 pp. + CD-ROM. 
Cerretti P (2012) New Afrotropical species belonging to genera never recorded before for Afrotropical fauna (Diptera: Tachinidae). Zoologischer Anzeiger 251: 317-330. [published online: 18 January 2012]. doi: 10.1016/j.jcz.2011.12.004

Cerretti P, Shima H (2011) World revision of Dolichocolon Brauer \& Bergenstamm (Diptera: Tachinidae: Exoristinae: Goniini). Zoological Journal of the Linnean Society 162: 544 584. doi: 10.1111/j.1096-3642.2010.00689.x

Cerretti P, Tschorsnig HP, Lopresti M, Di Giovanni F (2012) MOSCHweb - a matrix-based interactive key to the genera of the Palearctic Tachinidae (Insecta: Diptera). ZooKeys 205: 5-18. doi: 10.3897/zookeys.205.3409

Coquillett DW (1897) Revision of the Tachinidae of America north of Mexico. A family of parasitic two-winged insects. United States Department of Agriculture. Division of Entomology. Technical Series 7: 1-156.

Coquillett DW (1902) New Diptera from North America. Proceedings of the United States National Museum 25 [= No. 1280]: 83-126.

Cortés R, Campos L (1971) Taquinidos de Tarapaca y Antofagasta (Diptera: Tachinidae). Anales de la Universidad del Norte 8: 1-104.

Cortés R, Hichins N (1969) Distribución geográfica y huéspedes conocidos de los taquinidos de Chile (Diptera: Tachinidae). Ediciones de la Universidad de Chile, Santiago, 100 pp.

Crosskey RW (1984) Annotated keys to the genera of Tachinidae (Diptera) found in tropical and southern Africa. Annals of the Natal Museum 26: 189-237.

Grimaldi D, Engel MS (2005) Evolution of the Insects. Cambridge University Press. xv +755 pp. Guimarães JH (1972) A revision of the genus Winthemia Robineau-Desvoidy in America north of Mexico (Diptera, Tachinidae). Arquivos de Zoologia 22: 27-112.

Herting B (1966) Beiträge zur Kenntnis der europäischen Raupenfliegen (Dipt. Tachinidae) IX. Stuttgarter Beiträge zur Naturkunde. Serie A (Biologie) 146: 1-12.

Herting B (1984) Catalogue of Palearctic Tachinidae (Diptera). Stuttgarter Beiträge zur Naturkunde. Serie A (Biologie) 369: 1-228.

Kugler J (1971) Tachinidae of Israel IV. Description of ten new species. Israel Journal of Zoology 20: 69-88.

Kugler J (1980) New taxa of Tachinidae (Diptera) with a list of the species from Israel and adjacent territories. Israel Journal of Entomology 13: 27-60.

McAlpine JF (1981) Morphology and terminology - Adults. In: McAlpine JF, Peterson BV, Shewell GE, Teskey HJ, Vockeroth JR, Wood DM (Eds) Manual of Nearctic Diptera. Volume 1. Agriculture Canada Monograph 27: 9-63.

Mesnil LP (1966) Note de nomenclature [Dipt. Tachinidae]. Bulletin de la Société Entomologique de France 70 [1965]: 232.

O'Hara JE (2002) Revision of the Polideini (Tachinidae) of America north of Mexico. Studia Dipterologica. Supplement 10: 1-170.

O'Hara JE (2012) Review of Euthera (Diptera: Tachinidae) in North America with the description of a new species. Canadian Entomologist, 144: 206-215. doi: 10.4039/tce.2012.23

O'Hara JE, Wood DM (2004) Catalogue of the Tachinidae (Diptera) of America north of Mexico. Memoirs on Entomology, International, 18: iv + 1-410. 
Reinhard HJ (1931) Revision of the American parasitic flies belonging to the genus Winthemia. Proceedings of the United States National Museum 79 (Art. 20) [= No. 2886]: 1-54 + 1 pl. Robineau-Desvoidy JB (1830) Essai sur les myodaires. Mémoires présentés par divers savans à l'Académie Royale des Sciences de l'Institut de France. Sciences Mathématiques et Physiques (2) 2: 1-813.

Robineau-Desvoidy JB (1863) Histoire naturelle des diptères des environs de Paris Tomepremier. V. Masson et fils, Paris, F. Wagner, Leipzig, and Williams \& Norgate, London, xvi + $1-1143$.

Sabrosky CW (1973) Identification of Winthemia of America north of Mexico, with a revised key to the females (Diptera, Tachinidae). Annals of the Entomological Society of America 66: 1035-1041.

Sabrosky CW, Arnaud PH Jr (1965) Family Tachinidae (Larvaevoridae). In: Stone A, Sabrosky CW, Wirth WW, Foote RH, Coulson JR (Eds) A catalog of the Diptera of America north of Mexico. United States Department of Agriculture. Agriculture Handbook 276: 961-1108. Shima H (1976) Discovery of the Australasian genus Mycteromyiella Mesnil (Diptera: Tachinidae) from Japan, with descriptions of new species from Japan, Malay and Borneo. Kontyû 44: 311-322.

Shima H (1979) New genera, species and subspecies of Oriental Tachinidae (Diptera). Bulletin of the National Science Museum. Series A (Zoology) 5: 135-152.

Stuckenberg BR (1999) Antennal evolution in the Brachycera (Diptera) with a reassessment of terminology relating to the flagellum. Studia Dipterologica 6: 33-48.

Tothill JD (1912) Systematic notes on North American Tachinidae. Canadian Entomologist 44: 1-5. doi: 10.4039/Ent441-1

Townsend CHT (1927) Fauna sumatrensis. (Beitrag Nr. 50). Diptera Muscoidea III. Supplementa Entomologica 16: 56-76.

Tschorsnig HP (1985) Taxonomie forstlich wichtiger Parasiten: Untersuchungen zur Struktur des männlichen Postabdomens der Raupenfliegen (Diptera, Tachinidae). Stuttgarter Beiträge zur Naturkunde. Serie A (Biologie) 383: 1-137.

Tschorsnig HP (1988) Morphologie der Eier und Eilarven der Ethillini (Diptera: Tachinidae). Stuttgarter Beiträge zur Naturkunde. Serie A (Biologie) 418: 1-10.

Tschorsnig HP, Richter VA (1998) 3.54. Family Tachinidae. In: Papp L, Darvas B (Eds) Contribution to a Manual of Palaearctic Diptera (with special reference to flies of economic importance). Vol. 3. Higher Brachycera. Science Herald, Budapest, 691-827.

Verbeke J (1970) Diptera (Brachycera): Tachinidae (excl. Siphonina). South African Animal Life 14: 268-300.

Villeneuve J (1943) A propos de Zenillia bicincta Villen. (Dipt.). Bulletin de la Société Entomologique de France 48: 100-101.

Wood DM (1972) A revision of the New World Exoristini (Diptera: Tachinidae). I. Phorocera subgenus Pseudotachinomyia. Canadian Entomologist 104: 471-503. doi: 10.4039/Ent104471-4

Wood DM (1987) 110. Tachinidae. In: McAlpine JF, Peterson BV, Shewell GE, Teskey HJ, Vockeroth JR, Wood DM (Eds) Manual of Nearctic Diptera. Volume 2. Agriculture Canada Monograph 28, 1193-1269. 
Wulp FM (van der) (1890) Fam. Muscidae [cont.]. In: Godman FD, Salvin O (Eds) Biologia Centrali-Americana, or, contributions to the knowledge of the fauna and flora of Mexico and Central America. Zoologia. Class Insecta. Order Diptera. Vol. II. Taylor \& Francis, London, 57-88 [cont.]. 